\title{
PENGEMBANGAN MEDIA PEMBELAJARAN INTERAKTIF MENGGUNAKAN APLIKASI ADOBE DIRECTOR 11.5 MATA PELAJARAN BIOLOGI KELAS XI IPA
}

\begin{abstract}
Harleni $^{1}$
ABSTRACT

This research is in background by not yet effective implementation of Industrial Work Practice Program (Prakerin) SMK Negeri in Padang City. This is indicated by various problems in the implementation. The purpose of this evaluation is to assess the Prakerin SMK Negeri Kota Padang program, whether the program has been implemented in accordance with the planned program plan. This evaluation uses $\mathrm{CIPP}+\mathrm{O}$ evaluation model (Context, Input, Process, Product, and Outcome) with combination research method using Concurrent Embedded design with Qualitative data by interviewing 18 informants consisting of a chairman of the Prakerin committee, a treasurer of Prakerin, and a secretary of five heads of skill competency programs, five mentors and five instructors from business / industry. The research results revealed each component of Prakerin SMK Negeri Di Kota Padang program which was evaluated, that is context component with enough category, input component with good category, good category process component, good product component, and good category outcome component.
\end{abstract}

Keywords: Interactive Media; Adobe Director; Biology

\footnotetext{
1,2. Dosen Stikes Perintis Padang
} 


\section{INTI SARI}

Banyaknya materi yang harus dikuasai siswa membuat mereka menjadi jenuh belajar biologi. Masih jarang adanya sumber belajar berupa media interaktif yang diberikan kepada siswa, karena keterbatasan biaya, kemampuan dan waktu yang dimiliki oleh sekolah.Salah satu media alternatif agar siswa termotivasi serta lebih mudah memahami materi pelajaran dancepat memahami konsep yang abstrak adalahpenggunaan media interkatif dengan Aplikasi Adobe director 11.5. Penelitian ini bertujuan untuk menghasilkan media interaktif yang valid dan praktis digunakan dalam pembelajaran.Jenis penelitian ini adalah penelitian pengembangan yang menggunakan model 4D yaitu define, design, develop, dan disseminate, tetapi tahap disseminate tidak dilakukan. Penelitiandilakukanmelalui uji validitas oleh 2 orang validator materi, 2 orang validator media dan uji praktikalitas pada 20 orang siswa di SMA N 1 Sungai Tarab kelas XI IPA1. Data uji validitas dan praktikalitas dianalisis dengan analisis deskriptif.

Kata Kunci: Media Interaktif, Adobe Director, Biologi 


\section{PENDAHULUAN}

Pendidikan merupakan salah satu faktor yang dapat menentukan perkembangan suatu Negara. Rendahnya mutu pendidikan saat ini disebabkan oleh beberapa fakor yaitu, sarana prasarana yang masih kurang memadai, kurikulum, guru, siswa, serta strategi dan metode dalam pembelajaran. Dari beberapa faktor tersebut, guru adalah faktor yang paling utama berpengaruh dalam dunia pendidikan. Guru merupakan ujung tombak atau tiang dalam dunia pendidikan. Karena guru adalah sosok yang sangat berperan penting dalam menentukan keberhasilan proses belajar. Sehingga guru dituntut untuk bisa menciptakan suasana belajar yang menyenangkan guna menarik motivasi serta minat siswa dalam belajar.

Pada proses pembelajaran
suatu keberhasilan yang dapat
dicapai siswa bukan hanya
tergantung pada proses
pembelajarannya, tetapi juga
tergantung dari faktor siswa itu
sendiri, yaitu faktor yang berasal dari
dalam diri siswa dan faktor yang
berasal dari luar siswa atau
lingkungan.
Fakto

internalmeliputi kecerdasan, bakat, motivasi, gaya belajar, persepsi, minat dan perhatian, sikap dan kebiasaan belajar, kedisiplinan dan ketekunan.Sedangkan faktor eksternal yang mempengaruhi hasil belajar siswa meliputi kemampuan guru, model pembelajaran, metode mengajar,media pembelajaran, serta strategi yang digunakan guru dalam menyampaikan materi pelajaran di kelas.

Salah satu lingkungan belajar siswa yang dominan yang mempengaruhi hasil belajar di sekolah adalah kualitas belajar mengajar. Sehingga untuk mencapai keberhasilan kualitas belajar mengajar yang diharapkan perlu adanya suatu pendekatan yang relevan dengan tuntutan kurikulum yang terus berubah. Sehingga apapun pendekatan yang digunakan dalam kegiatan belajar mengajar, sudah seharusnya siswa diposisikan sebagai pusat perhatian utama.

Agar proses pembelajaran dapat menarik minat atau perhatian siswa, guru juga di tuntut untuk memilki perantara atau media yang relevan guna mencapai tujuan yang diharapkan. Ada banyak cara yang dapat digunakan untuk meningkatkan hasil belajar, salah satunya adalah dengan cara memilih media pembelajaran yang tepat.

Menurut Gagne dalam Sadiman (2009:6) menyatakan, "media adalah berbagai jenis komponen dalam lingkungan siswa yang dapat merangsangnya untuk belajar." Media pembelajaran dapat juga diartikan sebagai alat komunikasi yang menyampaikan atau mengantarkan pesan-pesan dalam pembelajaran.

$$
\text { Menurut Briggs dalam }
$$

Rayandra Ashar (2011:7) menyatakan "media adalah sebagai sarana fisik yang digunakan untuk mengirim pesan kepada peserta didik sehingga merangsang mereka untuk belajar."

Jadi media pembelajaran merupakan segala sesuatu yang dapat menyampaikan ataupun menyalurkan pesan dari suatu sumber kepada penerima (peserta didik) guna memudahkan guru dalam mengajar. Baik itu berupa buku, taperecorder, kaset, video camera, video recorder, film, slide, foto, gambar, grafik, televisi, dan komputer.

Pada kenyataannya guru
pada umumnya masih
menggunakan pembelajaran yang
bersifat konvensional. Terkadang,
guru cendrung masih menggunakan


metode ceramah dengan mengandalkan LKS dan buku paket saja sebagai sumber belajar, sedangkan siswa hanya mengandalkan guru saja dalam menerima informasi. Terutama pada proses pembelajaran, siswa umumnya lebih suka pembelajaran yang bersifat praktek dari pada pembelajaran yang bersifat teori.

Seiring dengan adanya perubahan kurikulum pendidikan, yang mana semua mata pelajaran akan diintegrasikan menjadi pembelajaran berbasis TIK, sehingga siswa perlu dilatih dari sekarang untuk membiasakan diri belajar dan berinteraksi langsung dengan menggunakan teknologi berbasis multimedia salah satunya dengan teknologi komputer, guna untuk mempersiapkan peserta didik agar mampu dan memiliki bekal untuk menyesuaikan diri dalam kehidupan global yang semakin maju dan pada akhirnya dapat mengadaptasikan peserta didik dengan lingkungan dan dunia kerja baru nantinya. Selain itu, media informasi dan komunikasi, baik perangkat keras (Hardware) maupun perangkat lunak (Software), akan membawa perubahan yang positif bagi guru dalam menyampaikan pesan/informasi kepada peserta didik. Guru tidak lagi berperan sebagai satu-satunya sumber informasi bagi kegiatan pembelajaran para siswanya. Akan tetapi siswa dapat memperoleh informasi dari berbagai media, salah satunya adalah dari media interaktif dengan menggunakan aplikasi Adobe Director 11.5.

Adobe Director 11.5 adalah sebuah program yang dirancang khusus untuk membuat (selfcontained) atau program yang dapat berjalan sendiri. Aplikasi ini dapat dijadikan sebagai media presentasi maupun sebagai media interaktif. Adobe director merupakan sebuah program aplikasi yang dapat menghasilkan media pembelajaran berupa teks, video, audio, maupun gambar animasi. Sehingga, kita dapat menciptakan sebuah media dengan mengkolaborasikan aplikasi tersebut. Dengan menggunakan media interaktif ini siswa dapat berinteraksi langsung dengan media, sehingga siswa akan lebih memahami tentang materi itu sendiri, dan dengan demikian media interkatif dapat menunjang motivasi dan minat belajar siswa.

Motivasi belajar merupakan faktor penting agar siswa belajar lebih baik. Salah satu media alternatif agar siswa termotivasi serta dapat lebih mudah memahami materi pelajaran dan lebih cepat memahami konsep yang abtrak adalah penggunaan media interkatif dengan Aplikasi Adobe director 11.5. Dengan menggunakan media interaktif ini maka dapat meningkatkan motivasi siswa dalam belajar, siswa dapat belajar mandiri, dan kemudian dapat menghemat waktu, serta dapat melengkapi kekurangan media yang tidak tersedia sebelumnya.

Biologi merupakan mata pelajaran sains yang berisi banyak konsep dan butuh pemahaman. Seperti yanbb nbnnbg dikemukakan oleh Lufri (2007: 26) menyatakan bahwa, materi biologi sangat kaya dengan konsep. Untuk itu, dalam proses pembelajaran guru harus dapat menyampaikan konsep tersebut supaya siswa memahaminya. Berdasarkan hasil wawancara penulis dengan guru biologi kelas XI di SMA N 1 Sungai Tarab , terungkap bahwa terdapat kesulitan siswa dalam memahami pelajaran khususnya materi Mengidentifikasi Organel Sel Hewan dan Sel Tumbuhan. Hal ini disebabkan banyaknya istilah dalam bahasa baku yang terdapat pada materi tersebut. 
Banyaknya materi yang harus dikuasai siswa membuat mereka enjadi jenuh belajar biologi. Di SMA N 1 Sungai Tarab belum ada sumber belajar berupa media interaktif yang diberikan kepada siswa. Hal ini karena keterbatasan biaya, kemampuan dan waktu yang dimiliki oleh sekolah dalam menghasilkan media interaktif. Padahal media interaktif merupakan salah satu sumber belajar yang mampu meningkatkan efektifitas dan efisiensi pengajaran di sekolah. Menurut Daryanto (2010:52) secara umum manfaat media interaktif yang diperoleh adalah proses pembelajaran lebih menarik, lebih interaktif, jumlah waktu mengajar dapat dikurangi, kualitas belajar siswa dapat ditingkatkan dan proses belajar mengajar dapat dilakukan di mana dan kapan saja, serta sikap belajar siswa dapat ditingkatkan. Dengan adanya media interaktif siswa juga dapat belajar mandiri, sedangkan guru bisa berperan sebagai fasilisator.

Berdasarkan latar belakang yang telah diuraikan di atas, untuk menghasilkan media interaktif yang valid dan praktis maka telah dilakukan penelitian mengenai pengembangan media pembelajaran interaktif menggunakan aplikasi adobe director 11.5 pada mata pelajaran biologi kelas XI SMA. Tujuan penelitian ini adalah untuk menghasilkan media pembelajaran interaktif yang valid dan praktis sehingga layak digunakan dalam proses belajar mengajar.

\section{PENDEKATAN PEMECAHAN MASALAH \\ METODE PENELITIAN}

Jenis penelitian ini adalah penelitian pengembangan yang dikenal dengan istilah Research and Development (R\&D). Menurut Sugiyono (2009:407), "metode penelitian dan pengembangan adalah metode penelitian yang digunakan untuk menghasilkan produk tertentu, dan menguji keefektifan produk tertentu".Penelitian ini dilakukan dengan menggunakan model 4D yaitu define, design, develop, dan disseminate. Namun, dalam penelitian ini tahap disseminate tidak dilakukan. Tahap defineterdiri atas analisis kurikulum, analisis siswa, analisis media. Tahap designdilakukan perancangan media interaktif. Tahap developdilakukan melalui melalui uji validitas oleh validator dan uji praktikalitas pada siswa kelas XI IPA1 di SMA N 1 Sungai Tarab.

Data dalam penelitian ini berupa data primer yaitu data yang diperoleh langsung dari 2 orang dosen KTP FIP UNP dan 2 orang guru Biologi kelas XI SMA N 1 Sungai Tarab sebagai validator, dan 20 orang siswa kelas XI IPA1SMA N 1 Sungai Tarab untuk mengetahui praktikalitas dari media yang dikembangkan.

Teknik analisis yang digunakan adalah analisis deskriptif yang mendeskripsikan validitas dan kepraktisan media, sehingga dapat memberikan deskripsi yang berguna untuk memecahkan masalah rancangan dan produk. Data yang dikumpulkan dari penelitian ini adalah hasil analisis kurikulum, analisis siswa, analisis media, pengembang Adobe Director 11.5 sebagai media interaktif serta uji validitas dan praktikalitas pada siswa terhadap media interaktif yang dihasilkan. Data uji validitas dan praktikalitas dianalisis dengan analisis deskriptif.

\section{HASIL DAN PEMBAHASAN}

Berdasarkan penelitian yang telah dilakukan diperoleh data mengenai validitas dari validator materi dapat di lihat pada tabel 1 dan untuk melihat validitas dari 
validator media dapat dilihat pada tabel 2, sedangkan untuk melihat hasil praktikalitas pada siswa dapat di lihat pada tabel 3.

Tabel 1. Hasil Data Uji Coba Media Interaktif Pada Validator Materi

\begin{tabular}{|c|c|c|c|c|c|c|c|c|}
\hline \multirow[t]{2}{*}{ No } & \multirow[t]{2}{*}{ Aspek } & \multirow{2}{*}{$\begin{array}{l}\text { Variabel } \\
\text { Kriteria } \\
\text { Interkatif }\end{array}$} & \multicolumn{2}{|c|}{$\begin{array}{c}\text { Skor } \\
\text { Validator }\end{array}$} & \multicolumn{2}{|c|}{ Nilai Validitas } & \multirow{2}{*}{$\begin{array}{l}\text { Rata- } \\
\text { Rata }\end{array}$} & \multirow[t]{2}{*}{ Keterangan } \\
\hline & & & 1 & 2 & 3 & 4 & & \\
\hline \multirow[t]{5}{*}{1.} & \multirow[t]{5}{*}{ Materi } & $\begin{array}{l}\text { Kebenaran } \\
\text { konsep }\end{array}$ & 3,75 & $\begin{array}{l}3 \\
75\end{array}$ & $\begin{array}{l}93 \\
75\end{array}$ & $\begin{array}{l}93 \\
75\end{array}$ & $\begin{array}{l}93 \\
75\end{array}$ & $\begin{array}{l}\text { Valid dengan } \\
\text { revisi ringan }\end{array}$ \\
\hline & & $\begin{array}{l}\text { Kedalaman } \\
\text { materi }\end{array}$ & 3,6 & 3,6 & 90 & 90 & 90 & $\begin{array}{l}\text { Valid dengan } \\
\text { revisi ringan }\end{array}$ \\
\hline & & $\begin{array}{l}\text { Kekinian dan } \\
\text { kelengkapan }\end{array}$ & 3 & 3 & 75 & 75 & 75 & $\begin{array}{l}\text { Valid dengan } \\
\text { revisi sedang }\end{array}$ \\
\hline & & Keterbacaan & 4 & 3,5 & 100 & 87,5 & 93,5 & $\begin{array}{l}\text { Valid dengan } \\
\text { revisi ringan }\end{array}$ \\
\hline & & $\begin{array}{l}\text { Desain } \\
\text { pembelajaran }\end{array}$ & 4 & 4 & 100 & 100 & 100 & $\begin{array}{c}\text { Valid tanpa } \\
\text { revisi }\end{array}$ \\
\hline \multicolumn{7}{|c|}{ Rata-Rata } & $\begin{array}{l}91, \\
3 \%\end{array}$ & $\begin{array}{l}\text { Valid dengan } \\
\text { revisi ringan }\end{array}$ \\
\hline
\end{tabular}

Tabel 2. Hasil Data Uji Coba Media Interaktif Pada Validator Media

\begin{tabular}{|c|c|c|c|c|c|c|c|c|}
\hline \multirow[t]{2}{*}{ No } & \multirow[t]{2}{*}{ Aspek } & \multirow{2}{*}{$\begin{array}{l}\text { Variabel Kriteria } \\
\text { Interkatif }\end{array}$} & \multicolumn{2}{|c|}{$\begin{array}{c}\text { Skor } \\
\text { Validator }\end{array}$} & \multicolumn{2}{|c|}{$\begin{array}{c}\text { Nilai } \\
\text { validitas }\end{array}$} & \multirow{2}{*}{$\begin{array}{l}\text { Rata- } \\
\text { Rata }\end{array}$} & \multirow[t]{2}{*}{ Keterangan } \\
\hline & & & 1 & 2 & 3 & 4 & & \\
\hline \multirow[t]{3}{*}{1.} & \multirow[t]{3}{*}{ Media } & 1.1. Tampilan & 3 & 3,5 & 75 & 87,5 & 81,25 & $\begin{array}{l}\text { Valid dengan } \\
\text { revisi ringan }\end{array}$ \\
\hline & & $\begin{array}{l}\text { 1.2. Pemanfaatan } \\
\text { media }\end{array}$ & 3 & 3,5 & 75 & 87,5 & 81,25 & $\begin{array}{l}\text { Valid dengan } \\
\text { revisi ringan }\end{array}$ \\
\hline & & 1.3. $\quad$ Navigasi & 3 & 3,5 & 75 & 87,5 & 81,25 & $\begin{array}{l}\text { Valid dengan } \\
\text { revisi ringan }\end{array}$ \\
\hline \multicolumn{7}{|c|}{ Rata-Rata } & $81,25 \%$ & $\begin{array}{l}\text { Valid dengan } \\
\text { revisi ringan }\end{array}$ \\
\hline
\end{tabular}

Tabel 3. Hasil Data Praktikalitas Media Interaktif Pada Siswa

\begin{tabular}{|c|c|l|c|c|c|c|}
\hline No & Aspek & $\begin{array}{c}\text { Variabel Kriteria } \\
\text { Media Interaktif }\end{array}$ & Item & $\begin{array}{c}\text { Rata- } \\
\text { rata }\end{array}$ & $\begin{array}{c}\text { Persentase } \\
(\%)\end{array}$ & Keterangan \\
\hline \multirow{2}{*}{1} & \multirow{2}{*}{ Kepraktisan } & Tampilan & $1-5$ & 3.55 & $88.8 \%$ & Sangat Praktis \\
\cline { 3 - 6 } & & Penyajian Materi & $6-8$ & 2.95 & $73.75 \%$ & Praktis \\
\cline { 3 - 6 } & & Kemanfaatan & $9-11$ & 3.65 & $91.25 \%$ & Sangat Praktis \\
\hline \multicolumn{2}{|l}{ Rata-Rata } & 3.88 & $84.5 \%$ & Sangat Praktis \\
\hline
\end{tabular}

Dari penyajian data uji coba pada validator diatas yang terlihat pada tabel 1 bahwa media yang dikembangkan dari aspek materi tentang variabel kebenaran konsep, kedalaman materi, kekinian dan kelengkapan, serta desain pembelajaran termasuk pada kategori valid dengan revisi ringan, dan hasil data uji coba pada validator media yang terlihat pada tabel 2, bahwa media yang dikembangkan dari aspek media yang terdiri dari variabel kriteria tampilan, pemanfaatan media dan navigasi termasuk pada kategori valid dengan revisi ringan. Sedangkan hasil uji kepraktisan 
pada siswa yang terlihat pada tabel 3 bahwa media yang dikembangkan termasuk kategori sangat praktis, baik dari aspek tampilan, penyajian materi dan kemanfaatan.

Secara umum penilaian validator terhadap media yang dikembangkan tentang aspek materi diperoleh nilai rata-rata sebesar $91,3 \%$.Berdasarkan kriteria yang terdapat pada analisis validitas tentang aspek materi, maka media yang dihasilkan termasuk ke dalam kriteria valid dengan revisi ringanartinya materi yang terdapat pada media yang dikembangkan dapat digunakan setelah dilakukan beberapa revisi ringan, data dari hasil penilaian tersebut dapat di lihat pada tabel 4.

Tabel 4. Hasil Validasi Terhadap Media Tentang Aspek Materi

\begin{tabular}{|c|c|c|c|c|c|c|c|c|c|}
\hline \multirow[t]{2}{*}{ No } & \multirow[t]{2}{*}{ Aspek } & \multirow{2}{*}{$\begin{array}{l}\text { Variabel } \\
\text { Kriteria }\end{array}$} & \multirow[t]{2}{*}{ Item } & \multicolumn{2}{|c|}{$\begin{array}{c}\text { Skor } \\
\text { Validator }\end{array}$} & \multicolumn{2}{|c|}{ Nilai Validitas } & \multirow{2}{*}{$\begin{array}{l}\text { Rata- } \\
\text { Rata }\end{array}$} & \multirow[t]{2}{*}{ Keterangan } \\
\hline & & & & V1 & V2 & V1 & V2 & & \\
\hline \multirow[t]{20}{*}{1.} & \multirow[t]{19}{*}{ Materi } & \multirow{5}{*}{$\begin{array}{l}\text { Kebenaran } \\
\text { konsep }\end{array}$} & 1 & 4 & 4 & \multirow{5}{*}{93,75} & \multirow{5}{*}{93,75} & \multirow{5}{*}{93,75} & \multirow{5}{*}{$\begin{array}{l}\text { Valid revisi } \\
\text { ringan }\end{array}$} \\
\hline & & & 2 & 4 & 4 & & & & \\
\hline & & & 3 & 3 & 3 & & & & \\
\hline & & & 4 & 4 & 4 & & & & \\
\hline & & & $\begin{array}{l}\text { Rata- } \\
\text { rata }\end{array}$ & 3.75 & 3,75 & & & & \\
\hline & & \multirow{6}{*}{$\begin{array}{l}\text { Kedalaman } \\
\text { materi }\end{array}$} & 5 & 3 & 3 & \multirow{6}{*}{90} & \multirow{6}{*}{90} & \multirow{6}{*}{90} & \multirow{6}{*}{$\begin{array}{l}\text { Valid revisi } \\
\text { ringan }\end{array}$} \\
\hline & & & 6 & 4 & 4 & & & & \\
\hline & & & 7 & 4 & 4 & & & & \\
\hline & & & 8 & 3 & 3 & & & & \\
\hline & & & 9 & 4 & 4 & & & & \\
\hline & & & $\begin{array}{l}\text { Rata- } \\
\text { rata }\end{array}$ & 3,6 & 3,6 & & & & \\
\hline & & \multirow[t]{2}{*}{$\begin{array}{l}\text { Kekinian dan } \\
\text { kelengkapan }\end{array}$} & 10 & 3 & 3 & \multirow{2}{*}{75} & \multirow{2}{*}{75} & \multirow{2}{*}{75} & \multirow{2}{*}{$\begin{array}{l}\text { Valid revisi } \\
\text { sedang }\end{array}$} \\
\hline & & & $\begin{array}{l}\text { Rata- } \\
\text { rata }\end{array}$ & 3 & 3 & & & & \\
\hline & & \multirow[t]{3}{*}{ Keterbacaan } & 11 & 4 & 3 & \multirow{3}{*}{100} & \multirow{3}{*}{87,5} & \multirow{3}{*}{93,5} & \multirow{3}{*}{$\begin{array}{l}\text { Valid revisi } \\
\text { ringan }\end{array}$} \\
\hline & & & 12 & 4 & 4 & & & & \\
\hline & & & $\begin{array}{l}\text { Rata- } \\
\text { rata }\end{array}$ & 4 & 3,5 & & & & \\
\hline & & \multirow{3}{*}{$\begin{array}{l}\text { Desain } \\
\text { pembelajaran }\end{array}$} & 13 & 4 & 4 & \multirow{3}{*}{100} & \multirow{3}{*}{100} & & \\
\hline & & & 14 & 4 & 4 & & & 100 & Valid tanpa \\
\hline & & & $\begin{array}{l}\text { Rata- } \\
\text { rata }\end{array}$ & 4 & 4 & & & 100 & revisi \\
\hline & & Jumlah & & 52 & 51 & 458,75 & 446,25 & $91,3 \%$ & $\begin{array}{l}\text { Valid revisi } \\
\text { ringan }\end{array}$ \\
\hline
\end{tabular}

Hasil penilaian oleh validator terhadap media yang dikembangkan tentang aspek media diperoleh nilai rata-rata sebesar $81,25 \%$.Berdasarkan kriteria yang terdapat pada analisis validitas tentang aspek media, maka media yang dihasilkan termasuk ke dalam kriteria valid dengan revisi ringan, media yang dikembangkan dapat digunakan setelah dilakukan beberapa revisi ringan. Data dari hasil penilaian tersebut dapat dilihat pada tabel 5. 
Tabel 5. Hasil Validasi Terhadap Media Tentang Aspek Media

\begin{tabular}{|c|c|c|c|c|c|c|c|c|c|}
\hline \multirow[t]{2}{*}{ No } & \multirow{2}{*}{ Aspek } & \multirow{2}{*}{$\begin{array}{l}\text { Variabel } \\
\text { Kriteria }\end{array}$} & \multirow{2}{*}{ Item } & \multicolumn{2}{|c|}{$\begin{array}{c}\text { Skor } \\
\text { Validator }\end{array}$} & \multicolumn{2}{|c|}{$\begin{array}{c}\text { Nilai } \\
\text { Validitas }\end{array}$} & \multirow{2}{*}{$\begin{array}{l}\text { Rata- } \\
\text { Rata }\end{array}$} & \multirow[t]{2}{*}{ Keterangan } \\
\hline & & & & V1 & V2 & V1 & V2 & & \\
\hline \multirow[t]{18}{*}{1.} & \multirow[t]{17}{*}{ Media } & \multirow[t]{11}{*}{ Tampilan } & 1 & 3 & 4 & \multirow{11}{*}{75} & \multirow{11}{*}{87,5} & \multirow{11}{*}{81,25} & \multirow{11}{*}{$\begin{array}{l}\text { Valid revisi } \\
\text { ringan }\end{array}$} \\
\hline & & & 2 & 3 & 4 & & & & \\
\hline & & & 3 & 3 & 3 & & & & \\
\hline & & & 4 & 3 & 3 & & & & \\
\hline & & & 5 & 3 & 3 & & & & \\
\hline & & & 6 & 3 & 4 & & & & \\
\hline & & & 7 & 3 & 3 & & & & \\
\hline & & & 8 & 3 & 3 & & & & \\
\hline & & & 9 & 3 & 4 & & & & \\
\hline & & & 10 & 3 & 4 & & & & \\
\hline & & & $\begin{array}{l}\text { Rata- } \\
\text { rata }\end{array}$ & 3 & 3,5 & & & & \\
\hline & & \multirow{3}{*}{$\begin{array}{l}\text { Pemanfaat-an } \\
\text { media }\end{array}$} & 11 & 3 & 3 & \multirow{3}{*}{75} & \multirow{3}{*}{87,5} & \multirow{3}{*}{81,25} & \multirow{3}{*}{$\begin{array}{l}\text { Valid revisi } \\
\text { ringan }\end{array}$} \\
\hline & & & 12 & 3 & 4 & & & & \\
\hline & & & $\begin{array}{l}\text { Rata- } \\
\text { rata }\end{array}$ & 3 & 3,5 & & & & \\
\hline & & \multirow[t]{3}{*}{ Navigasi } & 13 & 3 & 4 & \multirow{3}{*}{75} & \multirow{3}{*}{87,5} & \multirow{3}{*}{81,25} & \multirow{3}{*}{$\begin{array}{l}\text { Valid revisi } \\
\text { ringan }\end{array}$} \\
\hline & & & 14 & 3 & 3 & & & & \\
\hline & & & $\begin{array}{l}\text { Rata- } \\
\text { rata }\end{array}$ & 3 & 3,5 & & & & \\
\hline & \multicolumn{3}{|c|}{ Jumlah } & 42 & 49 & 225 & 262,5 & $81,25 \%$ & $\begin{array}{c}\text { Valid revisi } \\
\text { ringan }\end{array}$ \\
\hline
\end{tabular}

Praktikalitas berkaitan dengan kemudahan dan kemajuan yang didapatkan siswa dengan menggunakan bahan ajar, instrumen, maupun produk lainnya. Kepraktisan secara empiris dilakukan melalui uji kepraktisan bahan ajar dalam proses pembelajaran sebagai uji pengembangan.

Dalam tahap ini dilakukan uji coba terbatas kepada siswa terhadap produk yang telah direvisi. Uji ini dilakukan untuk mengetahui kepraktisan produk yang dihasilkan berdasarkan tampilan, penyajian materi dan kemanfaatan oleh siswa atau user.Untuk mengetahui kepraktisan media yang dikembangkan, maka dilakukan analisis kepraktisan data dari siswa kelas XI IPA1 yang berjumlah 20 orang, serta untuk mengetahui respon dari siswa terhadap media yang dikembangkan tentang aspek tampilan, penyajian materi, dan kemanfaatan media dapat dilihat pada tabel 6 .

Tabel 6. Hasil Praktikalitas Media yang dikembangkan Pada Siswa

\begin{tabular}{|c|c|l|c|c|c|c|}
\hline \multirow{2}{*}{ No } & Aspek & $\begin{array}{c}\text { Variabel } \\
\text { Kriteria Media } \\
\text { Interaktif }\end{array}$ & Item & Rata-rata & $\begin{array}{c}\text { Persentase } \\
(\%)\end{array}$ & Keterangan \\
\hline 1 & Kepraktisan & Tampilan & $1-5$ & $\mathbf{3 . 5 5}$ & $\mathbf{8 8 . 8 \%}$ & $\begin{array}{c}\text { Sangat } \\
\text { Praktis }\end{array}$ \\
\cline { 3 - 6 } & & Penyajian Materi & $6-8$ & $\mathbf{2 . 9 5}$ & $\mathbf{7 3 . 7 5 \%}$ & Praktis \\
\cline { 2 - 6 } & $\begin{array}{l}1.3 \\
\text { Kemanfaatan }\end{array}$ & $9-11$ & $\mathbf{3 . 6 5}$ & $\mathbf{9 1 . 2 5 \%}$ & $\begin{array}{c}\text { Sangat } \\
\text { Praktis }\end{array}$ \\
\hline \multicolumn{2}{|c|}{ Rata-Rata } & $\mathbf{3 . 8 8}$ & $\mathbf{8 4 . 5 \%}$ & $\begin{array}{c}\text { Sangat } \\
\text { Praktis }\end{array}$ \\
\hline
\end{tabular}


Dari tabel 6 dapat dilihat bahwa secara umum penilaian uji praktikalitas pada siswa terhadap media yang dikembangkan adalah sangat praktisdengannilai kepraktisan 84,5\%.Pada aspek tampilan yang didapat adalah sangat praktisdengannilai kepraktisan $88,8 \%$, aspek penyajian materi adalahpraktisdengan

nilaikepraktisan $73,75 \%$ dan aspek kemanfaatan adalah sangat praktisdengannilai $\quad 91,25 \%$. Berdasarkan kriteria yang terdapat pada uji praktikalitas pada siswa maka media interaktif yang dihasilkan termasuk ke dalam kriteriasangat praktis untuk digunakan baik dari segi tampilan, penyajian materi dan kemanfaatan.

Produk media pembelajaran interktif digunakan sebagai media pembelajaran, sehingga dengan menggunakan komputer dalam belajar diharapkan siswa dapat belajar interaktif dan meningkatkan keberagaman belajar siswa dalam rangka pembelajaran mandiri. Menurut Sadiman (2012), belajar suatu proses yang kompleks yang terjadi pada semua orang dan berlangsung seumur hidup, sejak dia bayi, hingga liang lahat nanti. Salah satu pertanda bahwa seseorang telah belajar adanya perubahan tingkah laku dalam dirinya.

Berdasarkan pandangan itu maka belajar akan lebih baik bila bersifat aktif, kolaboratif dan terkondisi dalam konteks dunia yang riil. Sehingga dengan adanya aktifitas interaktif pengguna media pembelajaran dalam proses belajar akan menimbulkan pengalaman personal dalam interprestasi belajar.

Berikut ini hasil akhir validitas dan praktikalitas produk media pembelajaran interaktif setelah dikembangkan yang berada pada kategori valid dengan revisi ringandansangat praktissehinnga dinyatakan siap untuk digunakan.

Tabel 7. Flowchat. Hasil Akhir Validitas dan Praktikalitas

\begin{tabular}{|c|c|c|c|c|c|}
\hline \multicolumn{2}{|c|}{ Validitas } & \multicolumn{2}{c|}{ Praktikalitas } \\
\hline Materi & Kategori & Persentase & Kategori & Persentase & Kategori \\
\hline Persentase & Valid revisi & $\mathbf{8 1 , 2 5 \%}$ & $\begin{array}{c}\text { Valid revisi } \\
\text { ringan }\end{array}$ & $\mathbf{8 4 , 5 \%}$ & $\begin{array}{c}\text { Sangat } \\
\text { praktis }\end{array}$ \\
\hline $\mathbf{9 1 , 3} \%$ & \begin{tabular}{c} 
ringan \\
\hline
\end{tabular}
\end{tabular}

\section{Berdasarkan tabel diatas} dapat ditarik kesimpulan bahwa produk media pembelajaran interaktif ini memiliki kelayakan sebagai produk yang membantu guru khususnya dan siswa umummnya sebagai alternatif media pembelajaran. Produk ini dapat menunjang pembelajaran mandiri dengan memperhatikan perbedaan individu. Selain itu produk ini dapat membantu dan mempermudah proses belajar, memperjelas materi pelajaran dengan beragam visualisasi dan audiovisual.

\section{KESIMPULAN}

Berdasarkan gambaran hasil analisis data yang diperoleh selama penelitian dan pembahasan yang telah dikemungkakan pada bab sebelumnya, maka pada bagian ini akan dikemunkakan beberapa kesimpulan dan saran mengenai hasil kepraktisan dan kevalidan media interaktif. Hasil deskripsi data penilaian oleh validator dari aspek materi dan aspek media menunjukkan bahwa produk media pembelajaran interaktif dengan kategori revisi ringan validitas materi 
dengan nilai $91,3 \%$ dan validitas media dengan nilai $81,25 \%$. Sehingga rata-rata persentase dari validasi produk secara keseluruhan adalah $86,3 \%$ dengan kategori valid dengan revisi ringan.

Desrkripsi data uji lapangan menunjukkan bahwa produk media interkatif yang dilengkapi dengan aspek kepraktisan dengan variabel kriteria media interaktif tentang tampilan, penyajian materi, kemanfaatan berdasarkan pandangan siswa dengan nilai 84,5 $\%$ dengan kriteria sangat praktis. Dapat disimpulkan bahwa media interaktif yang dikembangkan pada penelitian ini termasuk media yang sangat praktis sehingga layak digunakan dalam proses pembelajaran. Berdasarkan kesimpulan
hasil penelitian yang telah
dipaparkan diatas,berikut ini dikemungkakan saran-saran yang berkenaan dengan kegiatan penelitian yang telah dilaksanakan. Sebaiknya uji coba terhadap produk yang dikembangkan dilakukan pada beberapa sekolah sehingga didapatkan hasil yang lebih valid. Dalam pengembangan media pembelajaran interaktif ini sebaiknya dilakukan oleh tim pengembang yang terdiri dari beberapa orang yang memiliki keahlian dalam bidang materi dan pada bidang media agar hasil yang diperoleh lebih berkualitas. Bagi seorang pengembang atau guru diharapkan meningkatkan pengetahuannya tentang komputer terutama mengenai desain, pemrograman dan desain grafis dalam membuat media pembelajaran interaktif sehingga untuk masa yang akan datang dapat mengembangkan media pembelajaran interaktif dengan materi yang lain. Dari hasil penelitian yang telah dilakukan, media pembelajaran interaktif ini layak digunakan oleh guru mata pelajaran
Biologi kelas XI SMA dan sederajat. Tahap pengembangan ini belum sempurna terkait pada batasan penelitian yang dilakukan belum sampai pada tahapan penyebaran atau disseminate yang mana merupakan tahap penggunaan produk pada skala yang lebih luas, sehingga penelitian ini disarankan agar dapat dikembangkan lagi dalam penelitian berikutnya.

\section{DAFTAR PUSTAKA}

[1] Abdul Kohar. 2014. Ancaman Keamanan pada Sistem Informasi Manajemen Rumah Sakit. Yogyakarta: Universitas Islam Indonesia.

[2] Alfi Arif. Quality Assurance dengan metode Quality Function Deployment: Konsep Implementasi Pada Institusi Perguruan Tinggi. Jember: Universitas Jember (artikel ini diakses tanggal 06 Februari 2018).

[3] Anton Setiawan Honggowibowo dan Titien Sediartie. 2005. Sistem Reservasi Pesawat Terbang Berbasis Web. Seminar Nasional Aplikasi Teknologi Informasi

[4] Erwantoni. 2016. Analisis dan Perancangan Sistem Informasi Penjualan dan Jasa Perbaikan Komputer Berbasis Web pada IPTEK Komputer Betara Kabupaten Tanjung Jabung Barat. Jambi: STIKOM Dinamika Bangsa Jambi.

[5] Fandy Tjiptono. 1997. Strategi Pemasaran. Yogyakarta: Penerbit Andi. 
[6] Hamim Tohari. 2014. Astah (Analisis serta Perancangan Sistem Informasi melalui Pendekatan UML. Yogyakarta: Andi Offset.

[7] Hanif Al Fatta. 2007. Analisis dan Perancangan Sistem Informasi untuk Keunggulan Bersaing dan Organisasi Modern. Yogyakarta: Penerbit Andi.

[8] M. Mursid. 2010. Manajemen Pemasaran. Jakarta: Bumi Aksara.

[9] Mohammad Subhan. 2012. Analisa Perancangan Sistem. Jakarta: Lentera IImu cendekia

[10] Rambat Lupiyoadi. 2014. Manajemen Pemasaran Jasa (Edisi 3). Jakarta: Salemba Empat.

[11] Zulpadli. 2016. Sistem Informasi Peta Digital Lokasi Sarana Prasarana Olahraga Provinsi Sumatera Barat. Padang: UNP. 